This article was downloaded by: [B-on Consortium - 2007]

On: 25 August 2009

Access details: Access Details: [subscription number 908038075]

Publisher Informa Healthcare

Informa Ltd Registered in England and Wales Registered Number: 1072954 Registered office: Mortimer House, 37-41 Mortimer Street, London W1T 3JH, UK

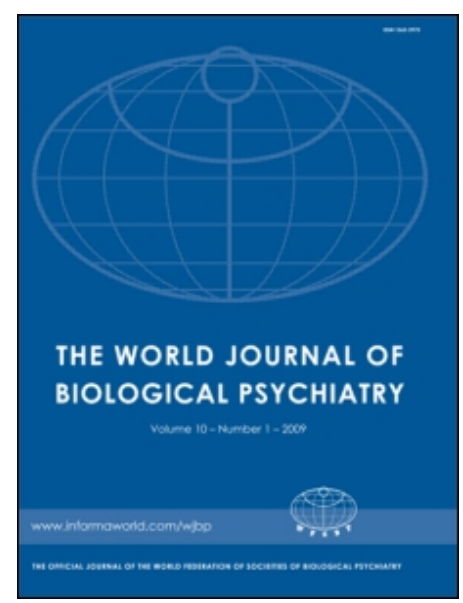

\title{
World Journal of Biological Psychiatry
}

Publication details, including instructions for authors and subscription information:

http://www.informaworld.com/smpp/title content=t713721967

\section{Perfectionism and sleep disturbance}

Maria Helena Pinto de Azevedo a; Maria João Soares a; Sandra Carvalho Bos a; Ana Allen Gomes b; Berta

Maia a; Mariana Marques ${ }^{\text {a; }}$ Ana Telma Pereira ${ }^{\text {a; }}$ António Macedo ${ }^{a}$

a Institute of Medical Psychology, Faculty of Medicine, University of Coimbra, Coimbra, Portugal ${ }^{b}$ Department

of Education, Campus Universitário de Santiago, University of Aveiro, Aveiro, Portugal

First Published:August2009

To cite this Article de Azevedo, Maria Helena Pinto, Soares, Maria João, Carvalho Bos, Sandra, Allen Gomes, Ana, Maia, Berta, Marques, Mariana, Pereira, Ana Telma and Macedo, António(2009)'Perfectionism and sleep disturbance',World Journal of Biological Psychiatry, 10:3,225 - 233

To link to this Article: DOI: $10.1080 / 15622970701367930$

URL: http://dx.doi.org/10.1080/15622970701367930

\section{PLEASE SCROLL DOWN FOR ARTICLE}

\author{
Full terms and conditions of use: http://www.informaworld.com/terms-and-conditions-of-access.pdf \\ This article may be used for research, teaching and private study purposes. Any substantial or \\ systematic reproduction, re-distribution, re-selling, loan or sub-licensing, systematic supply or \\ distribution in any form to anyone is expressly forbidden. \\ The publisher does not give any warranty express or implied or make any representation that the contents \\ will be complete or accurate or up to date. The accuracy of any instructions, formulae and drug doses \\ should be independently verified with primary sources. The publisher shall not be liable for any loss, \\ actions, claims, proceedings, demand or costs or damages whatsoever or howsoever caused arising directly \\ or indirectly in connection with or arising out of the use of this material.
}




\title{
Perfectionism and sleep disturbance
}

\author{
MARIA HELENA PINTO DE AZEVEDO ${ }^{1}$, MARIA JOÃO SOARES ${ }^{1}$, \\ SANDRA CARVALHO BOS ${ }^{1}$, ANA ALLEN GOMES ${ }^{2}$, BERTA MAIA ${ }^{1}$, \\ MARIANA MARQUES ${ }^{1}$, ANA TELMA PEREIRA ${ }^{1}$ \& ANTÓNIO MACEDO ${ }^{1}$ \\ ${ }^{1}$ Institute of Medical Psychology, Faculty of Medicine, University of Coimbra, Coimbra, Portugal, and ${ }^{2}$ Department of \\ Education, Campus Universitário de Santiago, University of Aveiro, Aveiro, Portugal
}

\begin{abstract}
The main purpose of the present research was to explore gender-related associations between sleep disturbance and perfectionism dimensions in a large sample of undergraduate students. Perfectionism dimensions have been assessed using the Portuguese version of the Multidimensional Perfectionism Scale (Hewitt and Flett, 1991, J Pers Soc Psychol 60:456; Soares et al., 2003, Rev Port Psicossom 5:46) and sleep disturbance with two items concerning difficulties initiating sleep and difficulties maintaining sleep. A total of 1163 undergraduate students of both genders between 17 and 25 years of age completed the scale. Results from correlational and categorial analyses indicated that socially prescribed perfectionism was the only dimension associated with sleep disturbance in undergraduate students of both genders. Males with the highest levels of socially prescribed perfectionism were approximately twice more likely to report sleep disturbances than those with less socially prescribed perfectionism. Similar results were found within the female sample. Implications for future research and clinical practice are discussed.
\end{abstract}

Key words: Self-oriented perfectionism, socially prescribed perfectionism, other-oriented perfectionism, sleep disturbance, university students

\section{Introduction}

In recent years, there has been growing recognition that perfectionism is a multidimensional construct (Hewitt and Flett 2002), with different components being differentially related to some adaptive and maladaptive qualities (Enns and Cox 2002). In this context, two instruments that bear the same name the Multidimensional Perfectionism scale (MPS) have been independently developed from different conceptual approaches: Hewitt and Flett MPS (1991) and Frost et al. MPS (1990). These two scales are related, though most relationships are moderate in size, suggesting that the underlying perfectionism dimensions and constructs are fairly distinct (Enns and Cox 2002).

The Hewitt and Flett MPS (1991) distinguishes three essential components of perfectionism: self-oriented perfectionism (SOP), an intrapersonal component, which entails perfectionist behaviours deriving from and directed to the self; socially prescribed perfectionism (SPP), an interpersonal dimension that involves the perception that significant others have excessively high standards and expectations of perfection for oneself; other-oriented perfectionism (OOP), an interpersonal component which involves perfectionist standards and demands deriving also from the self, but which are imposed on others. On the other hand, the Frost et al. (1990) scale measures the extent to which the person (a) is concerned over making mistakes (CM), (b) sets high personal standards (PS), (c) feels criticized by his or her parents (PC), (d) feels that his or her parents have high expectations for him or herself (PE), and (e) doubts his or her ability to perform actions (DA).

The importance of perfectionism is related to the fact that it has been linked with various somatic symptoms including chronic fatigue and headaches and a broad range of psychopathological conditions such as anxiety/depression (Shafran and Mansell 2001) and disordered eating (Macedo et al. 2006).

Correspondence: Professora Doutora Maria Helena P. de Azevedo, Faculdade de Medicina da Universidade de Coimbra, Instituto de Psicologia Médica, Rua Larga, 3004-504 Coimbra, Portugal. Tel:+351 239 857700. Fax:+351 239 823170. E-mail: mazevedo@fmed.uc.pt 
The aetiology of psychiatric symptoms/syndromes and psychological distress is multifactorial, involving the interplay of many factors, both biological (e.g., genetic) and environmental (e.g., childhood maltreatment, adverse events, psychosocial stress). The pathway between the genetic/developmental risk factors and the behavioural phenotypes is a long and complex one, and the nature of the underlying mechanisms still remains to be clarified. In order to disentangle the effects of the risk factors, namely the effects of the genetic factors influencing different psychopathological conditions, and partly overcome this complexity, it has been proposed that alternative phenotypic measures (endophenotypes or intermediary phenotypes), including personality traits such as perfectionism, may be used in the biological investigation of psychiatric disorders (e.g., molecular genetic studies). The issue here is that personality traits, which are partly under genetic control, may be closer to the genetic effects than psychiatric syndromes. As Thomas Insel and Francis Collins insightfully have recently stated "we may discover that some of the genes for vulnerability to anorexia nervosa are shared by OCD and depression, with the genotype linked not to a specific disorder but to a perfectionistic, risk-aversive personality style that confers vulnerability to many syndromes" (Insel and Collins 2003).

In spite of the rapid growth of the literature in this area, the relationship of perfectionism with sleep disturbances or insomnia has received little attention (Lundh et al. 1994; Vincent and Walker 2000). In the work done by Lundh et al. (1994), perfectionism was assessed by means of a shortened version of the Frost-MPS (Frost et al. 1990). In a study with a normal sample, perfectionism correlated with a composite score on degree of sleeping problems (Lundh et al. 1994). In their clinical sample from a sleep disorders clinic, patients with persistent insomnia had significantly higher scores than normals on perfectionism, especially on the subscales CM and PS. Within the insomnia group, patients with a concomitant diagnosis of major depression differed from the non-depressed insomniacs by having higher scores on the subscale DA. On the basis of these studies, Lundh et al. (1994) hypothesized that perfectionism (high PS and high CM) may serve as a predisposing factor for the development of persistent insomnia. In addition to Frost's scale, Vincent and Walker (2000) used the Hewitt and Flett-MPS (1991) in a sample of 32 adults who responded to an advertisement placed in a community newspaper offering treatment for chronic insomnia and 26 healthy controls. Significant associations were not found between SOP, SPP and OOP and insomnia, although subjects with insomnia tended to report more SPP than healthy controls. Using a univariate approach, results indicated that those with chronic insomnia were more likely to endorse features of "maladaptive" perfectionism relative to healthy controls. With respect to Frost's scale (1990), results showed that those with chronic insomnia were more likely to report DA, frequent PC, and CM. However, only perception of heightened PC was associated with the reporting of delayed sleep-onset latency. No other aspect of perfectionism was associated with sleep-onset latency, total sleep time, or sleep quality.

Considering previous empirical studies and the clinical experience of the first author that patients with insomnia present higher rates of self-reported ruminations, intrusive thoughts, worry and a tendency to be perfectionist, the hypothesis of the present study was that perfectionism and particularly the socially prescribed perfectionism dimension would be associated with sleep disturbance.

As the number of studies about this topic is scarce, the present study can contribute to the knowledge in this field of research. Moreover, this study can have clinical and treatment implications as a perfectionism personality is probably a risk and maintenance factor for insomnia.

The aim of the present research was to further investigate the association between Hewitt and Flett's perfectionism dimensions and self-reported sleep disturbances in a large sample of undergraduate Portuguese university students of both genders.

\section{Method}

Data for this report were drawn from a research project on Perfectionism and Obsessive-Compulsive Spectrum Disorders. This research was reviewed and approved by the Medical Ethics Review Committee of the University Hospital of Coimbra (Macedo et al. 2002).

\section{Participants}

The sample comprised 1163 full-time undergraduate university students (764 females and 399 males) with a mean age of 19.46 years (standard deviation $=1.6$; range $=17-25$ years). With regard to marital status the great majority was single (99\%).

\section{Procedure}

The voluntary nature and general format of the research were explained to the Faculty Professors of Medicine, Dentistry, and Humanities, of the Coimbra University, and all agreed to participate in the study. Then, with their approval, participants were 
given time at the beginning/ending of a class session to fill in the survey questionnaires (students spent approximately 25 min filling in the questionnaire). It was emphasized that their cooperation was voluntary, and confidentiality was ensured. All students present in class returned the questionnaires. Thus, refusal to participate in the study was typically indicated by non-return of the questionnaires given to them after introducing the research. Data were collected throughout the academic year of 2000 when exam evaluations were not taking place.

\section{Measures}

Perfectionism. Hewitt and Flett-MPS (1991) was used to measure self-oriented perfectionism, socially prescribed perfectionism and other-oriented perfectionism. The scale has 45 items, and the subject is asked to rate each item on a seven-point scale ranging from strongly disagree (score 1), to strongly agree (score 7). In its Portuguese version (Soares et al. 2003) the MPS total score, derived from the sum of scores for the individual, showed a high internal consistency (Cronbach's $\alpha=0.88$ ), and the test-retest reliability over 4 weeks $(n=293)$ was 0.84 (Pearson's $r, P<0.001)$. Theoretically the scores may range from 45 to 315 . A higher score is considered as an indicator of higher levels of perfectionism. Internal consistency (Cronbach's $\alpha$ ) for the subscales were: $\mathrm{SO}$ (18 items) $=0.89$; SP (15 items $)=0.84$ and $\mathrm{OO}(8$ items $)=0.66$.

Sleep disturbances. Two items, presented as statements, were used to assess sleep disturbances: (1) I have difficulty in falling asleep (difficulties initiating sleep); and (2) I wake up many times during the night (difficulties maintaining sleep). Each item is scored on a five-point scale ranging from 0 (never) to 5 (always). In addition to scores obtained for difficulties initiating sleep and difficulties maintaining sleep (possible range 0-5), an overall index of sleep disturbance score (SDI) was calculated from the sum of the scores of the individual items (possible range 0-10; Cronbach's $\alpha=0.64$ ). Higher scores indicate greater subjective sleep disturbance. The test-retest reliabilities (Pearson's $r$ ) over 4 weeks: was $0.64(P<0.001)$ for the difficulties initiating sleep; $0.59 \quad(P<0.001)$ for difficulties maintaining sleep score; and $0.72(P<0.001)$ for the sleep disturbance index score.

To further explore associations between perfectionism and sleep disturbance, subjects were divided into groups. The insomnia group $(n=243)$ included subjects who reported that "often, very often or always had difficulties initiating sleep and/or maintaining sleep". The good sleepers group $(n=483)$ was formed by subjects who reported that "never or rarely had difficulties initiating and maintaining sleep". Moreover, three other groups were created. The initial insomnia group $(n=172)$ included subjects who reported having "often, very often or always difficulties initiating sleep" and did not report "difficulties maintaining sleep". The maintenance insomnia group $(n=22)$ comprised subjects who stated that "often, very often or always had difficulties maintaining sleep" but who did not have "difficulties initiating sleep". The initial and maintenance group $(n=49)$ was formed by subjects who reported that "often, very often or always" had "difficulties initiating sleep" and also "maintaining sleep".

\section{Results}

\section{Perfectionism dimensions results}

Perfectionism total score mean for the total sample was $\mathrm{M}=185.60, \mathrm{SD}=27.18$ (M, Mean; $\mathrm{SD}$, standard deviation). The total score mean of perfectionism for females was $M=184.65(\mathrm{SD}=26.83)$ and males $\mathrm{M}=187.38(\mathrm{SD}=27.78)$. With respect to SOP, the mean score was $M=80.60(S D=15.76)$ for the total sample, $M=86.00(S D=16.26)$ for females and $M=83.60(S D=16.90)$ for males. SPP mean total score was $M=45.17 \quad(S D=11.91)$. Results for SPP were significantly higher in males than in females $(M=46.4, S D=11.8$ vs. $M=44.5$, $\mathrm{SD}=11.9 ; \quad t=2.53 ; \quad \mathrm{df}=1113 ; \quad P=0.01) . \quad \mathrm{OOP}$ mean score was $\mathrm{M}=44.69(\mathrm{SD}=7.02)$ for the total sample, $M=39.14(\mathrm{SD}=6.48)$ for females and $\mathrm{M}=45.05$ ( $\mathrm{SD}=7.24)$ for males.

\section{Sleep disturbance results}

Difficulty initiating sleep (DIS) described as "often, very often and/or always" was reported by $19.0 \%$ of the total sample, $20.1 \%$ of the female sample and $16.8 \%$ of the male sample. Difficulty maintaining sleep (DMS) reported as "often, very often and/or always" was mentioned by $6.1 \%$ of the total sample, $6.1 \%$ of the female sample and $6.3 \%$ of the male sample (see Table I).

Association between perfectionism and sleep disturbance scores

Pearson's product moment correlations (Pearson's $r$ ) between perfectionism and sleep disturbances scores are shown in Table II. Significant positive correlations, albeit modest in size (Cohen 1992), were observed between total perfectionism and DIS, DMS and SDI, not only in the total sample but also in the female sample. SPP was the only 
Table I. Frequency of insomnia symptoms by gender.

\begin{tabular}{|c|c|c|c|}
\hline & $\begin{array}{c}\text { Total sample } \\
\begin{array}{c}N=1163 \\
n(\%)\end{array}\end{array}$ & $\begin{array}{c}\text { Females } \\
n=764 \\
n(\%)\end{array}$ & $\begin{array}{c}\text { Males } \\
n=399 \\
n(\%)\end{array}$ \\
\hline \multicolumn{4}{|c|}{ Difficulty initiating sleep } \\
\hline Never/rarely & $541(46.6)$ & $345(45.1)$ & $196(49.1)$ \\
\hline Sometimes & $401(34.5)$ & $265(34.7)$ & $136(34.1)$ \\
\hline Often & $128(11.0)$ & $95(12.4)$ & $33(8.3)$ \\
\hline Very often/Always & $93(8.0)$ & $59(7.7)$ & $34(8.5)$ \\
\hline \multicolumn{4}{|c|}{ Difficulty maintaining sleep } \\
\hline Never/rarely & 805 (69.2) & $519(67.9)$ & $286(71.7)$ \\
\hline Sometimes & $287(24.7)$ & $199(26.0)$ & $88(22.1)$ \\
\hline Often & $46(4.0)$ & $31(4.1)$ & $15(3.8)$ \\
\hline Very often/Always & $25(2.1)$ & $15(2.0)$ & $10(2.5)$ \\
\hline
\end{tabular}

perfectionism dimension which was significantly associated with DIS, DMS and SDI within the three samples (total, female and male). However, a positive small correlation between SOP and sleep measures was observed in females. Associations between OOP and sleep disturbance were not found for the three samples considered.

Following the Lundh et al. (1994) approach, individual items of the SOP, SPP and OOP subscales were correlated with the SDI score. In females, of all significant correlations found, 2/18 items were part of the SOP and were related with setting high personal standards and with concerns about mistakes ( $r$ values were 0.14 and 0.13 , respectively; $P$ values $<0.05$ ), and $8 / 15$ items were from SPP ( $r$ values ranged from 0.13 to $0.20, P$ values $<0.01)$. In the male sample, three items of the SPP were correlated with sleep disturbance. SPP

Table II. Pearson correlations between perfectionism scores and sleep disturbance.

\begin{tabular}{llll}
\hline Perfectionism & \multicolumn{1}{c}{ DIS } \\
& \multicolumn{1}{c}{$\begin{array}{c}\text { DMS } \\
r\end{array}$} & $\begin{array}{c}\text { SDI } \\
r\end{array}$ \\
\hline Total sample $(N)$ & & & \\
$\quad$ MPS total (1053) & $0.13^{\star \star}$ & $0.14^{\star \star}$ & $0.15^{\star \star}$ \\
Self-oriented (1107) & 0.05 & $0.08^{\star \star}$ & $0.08^{\star}$ \\
Socially-prescribed (1115) & $0.20^{\star \star}$ & $0.20^{\star \star}$ & $0.23^{\star \star}$ \\
Other-oriented (1133) & 0.02 & 0.00 & 0.01 \\
Female sample ( $(n)$ & & & \\
Total score (688) & $0.14^{\star \star}$ & $0.17^{\star \star}$ & $0.18^{\star \star}$ \\
Self-oriented (725) & $0.08^{\star}$ & $0.10^{\star \star}$ & $0.10^{\star \star}$ \\
Socially-prescribed (728) & $0.20^{\star \star}$ & $0.23^{\star \star}$ & $0.25^{\star \star}$ \\
Other-oriented (741) & 0.01 & 0.00 & 0.01 \\
Male sample (n) & & & \\
MPS total (365) & $0.11^{\star}$ & 0.10 & $0.12^{\star}$ \\
Self-oriented (380) & 0.00 & 0.03 & 0.02 \\
Socially-prescribed (387) & $0.23^{\star \star}$ & $0.18^{\star \star}$ & $0.24^{\star \star}$ \\
Other-oriented (393) & 0.01 & -0.03 & -0.01 \\
\hline
\end{tabular}

DIS, difficulty initiating sleep; DMS, difficulty maintaining sleep; SDI, Sleep Disturbance Index; MPS, Multidimensional Perfectionism Scale; $r=$ Pearson's correlation coefficient.

$\star \star P<0.01 ; \star{ }^{\star} P<0.05$. items included perceptions that others or family have excessively high expectations about oneself ( $r$ values ranged from 0.21 to $0.26, P<0.01$ ).

To study associations between perfectionism and sleep disturbance, subjects were also divided into quartile groups according to their perfectionism scores (from the lowest, quartile 1, to the highest, quartile 4) and the SDI mean was calculated for each perfectionism quartile. Data were divided into four perfectionism subgroups to study if the sleep disturbance means scores increased with the level of perfectionism or if the mean scores of sleep disturbance were different only between high and low perfectionism sub-groups.

One-way analysis of variance was applied to compare group differences (see Table III). No significant group differences were observed for SOP and OOP.

In both females and males higher levels of perfectionism total score and of SPP were associated with higher scores of sleep disturbance. Tamhane's multiple comparisons test showed that females in the highest perfectionism quartile (quartile 4) had significantly higher means of sleep disturbances than those in the lowest quartile (quartile 1). With respect to SPP, women in the higher quartiles (quartiles 2, 3 and 4) had significantly higher means of sleep disturbance than those in the lowest group (quartile 1). Using as cut-off point the median for SPP and the median of the sleep disturbance index, women with more SPP were 1.8 times more likely to report sleep disturbances than women with less SPP $(\mathrm{OR}=$ 1.8; 95\%; CI: 1.372-2.479). Tamhane's multiple comparisons test also showed that males with more SPP (quartiles 3 and 4) had significantly higher means scores of sleep disturbances than those in the lowest quartile (quartile 1). Males with the highest SPP scores (quartile 4) were 2.6 times more likely to report sleep disturbances than the group with the lowest SPP scores (quartile 1) ( $\mathrm{OR}=2.6,95 \%$; CI: 1.501-4.642).

\section{Good sleepers group versus insomnia groups}

The good sleepers group included $41.5 \%(n=483)$ of subjects from the total sample, $40 \%(n=306)$ of subjects from the female sample and $44.4 \%$ $(n=177)$ of subjects from the male sample. The insomnia group was formed by $20.9 \%(n=243)$ of subjects from the total sample, $22 \%(n=168)$ from the female sample and $18.8 \%(n=75)$ from the male sample.

As indicated in Table IV, total perfectionism as well as SPP were higher in the insomniac group than in the good sleepers group. These results were observed not only when the complete sample was 
Table III. Sleep disturbance index scores by perfectionism quartile groups in total sample, female and male sample (one-way ANOVA).

\begin{tabular}{|c|c|c|c|c|c|c|c|}
\hline Perfectionism & $\begin{array}{c}\leq \mathrm{P} 25 \\
1 \\
\mathrm{M}(\mathrm{SD})\end{array}$ & $\begin{array}{c}\text { P25-P50 } \\
2 \\
\mathrm{M}(\mathrm{SD})\end{array}$ & $\begin{array}{c}\text { P50-P75 } \\
3 \\
M(S D)\end{array}$ & $\begin{array}{c}\geq \mathrm{P} 75 \\
4 \\
\mathrm{M}(\mathrm{SD})\end{array}$ & $F$ & $P$ & $\begin{array}{c}\text { Multiple } \\
\text { comparisons }\end{array}$ \\
\hline \multicolumn{8}{|l|}{ Total sample } \\
\hline MPS total & $2.61(1.55)$ & $2.97(1.72)$ & $2.96(1.62)$ & $3.26(1.92)$ & 6.510 & $<0.001^{\star \star}$ & $1<4^{\star \star}$ \\
\hline SOP & $2.83(1.74)$ & $2.92(1.65)$ & $2.94(1.64)$ & $3.07(1.81)$ & 0.934 & 0.423 & \\
\hline SPP & $2.50(1.47)$ & $2.90(1.69)$ & $2.97(1.62)$ & $3.43(1.91)$ & 15.379 & $<0.001^{\star \star}$ & $1<2^{\star \star}, 3^{\star \star}, 4^{\star \star}$ \\
\hline OOP & $2.92(1.77)$ & $2.89(1.69)$ & $3.01(1.68)$ & $2.93(1.72)$ & 0.287 & 0.835 & \\
\hline \multicolumn{8}{|l|}{ Females } \\
\hline MPS total & $2.68(1.66)$ & $2.84(1.59)$ & $2.99(1.65)$ & $3.28(1.80)$ & 4.177 & $0.006^{\star}$ & $1<4^{\star \star}$ \\
\hline SOP & $2.79(1.76)$ & $2.90(1.57)$ & $2.89(1.61)$ & $3.23(1.77)$ & 2.365 & 0.070 & \\
\hline SPP & $2.54(1.53)$ & $2.76(1.59)$ & $3.13(1.68)$ & $3.43(1.84)$ & 10.414 & $<0.001^{\star \star}$ & $1<2^{\star \star}, 3^{\star \star}, 4^{\star \star}$ \\
\hline OOP & $2.93(1.78)$ & $2.92(1.72)$ & $2.95(1.64)$ & $2.99(1.66)$ & 0.060 & 0.981 & \\
\hline \multicolumn{8}{|l|}{ Males } \\
\hline MPS total & $2.47(1.31)$ & $3.18(1.87)$ & $2.91(1.81)$ & $3.16(1.97)$ & 3.172 & $0.024^{\star}$ & $1<2^{\star}, 4^{\star}$ \\
\hline SOP & $2.93(1.70)$ & $2.83(1.72)$ & $3.03(1.73)$ & $2.90(1.90)$ & 0.214 & 0.887 & \\
\hline SPP & $2.42(1.22)$ & $2.88(1.69)$ & $3.03(1.88)$ & $3.42(2.00)$ & 5.729 & $0.001^{\star \star}$ & $1<3^{\star}, 4^{\star \star}$ \\
\hline OOP & $3.08(1.87)$ & $2.76(1.42)$ & $2.95(1.85)$ & $2.94(1.85)$ & 0.540 & 0.655 & \\
\hline
\end{tabular}

MPS, Multidimensional Perfectionism Scale; SOP, self-oriented perfectionism; SPP, socially prescribed perfectionism; OOP, other-oriented perfectionism; M, mean; SD, standard deviation.

${ }^{\star} \star P \leq 0.001 ; * P<0.05$.

Note: Multiple comparisons were performed using a Tamhane's test, except for the group comparisons in MPS total score in females, where a Bonferroni test was applied as the variance between groups was significantly different (Levene's test).

considered but also when the female and male samples data were explored separately. With respect to SOP or OOP significant differences were not observed between the good sleepers group and the insomniac group (once more these results were obtained when considering the total sample and when studying men and female samples in separate).

The next step was to compare perfectionism scores between the group of good sleepers and the three groups of insomnia symptoms (either initial insomnia alone, maintenance insomnia alone, or both types) (see Table V). The initial insomnia group included $14.8 \%(n=172)$ of subjects from the total sample, $16 \%(n=122)$ of subjects from the female sample and $12.5 \%(n=50)$ of subjects from the male sample. The maintenance insomnia group comprised $1.9 \%(n=22)$ of the subjects in the total sample, $1.8 \%(n=14)$ of subjects in the female sample and $2.0 \%(n=8)$ of subjects in the male sample. A third group formed combining both groups of initial and maintenance insomnia consists of $4.2 \%(n=49)$ the total sample, $4.2 \%(n=32)$ of

Table IV. Differences between insomniacs and good sleepers regarding the total score and the scores in perfectionism dimensions.

\begin{tabular}{|c|c|c|c|c|c|c|}
\hline \multirow[b]{2}{*}{ Perfectionism } & \multicolumn{2}{|c|}{ Good sleepers } & \multicolumn{2}{|c|}{ Insomniacs } & \multirow[b]{2}{*}{$t$} & \multirow[b]{2}{*}{$P$} \\
\hline & $n$ & $M(S D)$ & $n$ & $M(S D)$ & & \\
\hline Total sample & 483 & & 243 & & & \\
\hline MPS Total & 433 & $182.44(27.27)$ & 217 & $190.67(25.61)$ & -3.704 & $<0.001^{\star \star}$ \\
\hline SOP & 459 & $79.85(15.35)$ & 228 & $82.22(15.63)$ & -1.890 & 0.06 \\
\hline SPP & 457 & $43.04(11.28)$ & 232 & $48.79(12.32)$ & -6.136 & $<0.001^{\star \star}$ \\
\hline OOP & 471 & $44.70(6.92)$ & 233 & $44.53(7.30)$ & 0.295 & 0.77 \\
\hline Females & 306 & & 168 & & & \\
\hline MPS Total & 271 & $180.55(26.42)$ & 145 & $188.72(26.07)$ & -3.021 & $<0.001^{\star \star}$ \\
\hline SOP & 289 & $84.63(15.77)$ & 155 & $87.52(16.52)$ & -1.808 & 0.071 \\
\hline SPP & 287 & $42.23(11.41)$ & 157 & $47.95(12.58)$ & -4.871 & $<0.001^{\star \star}$ \\
\hline OOP & 298 & $39.10(6.27)$ & 159 & $38.60(6.86)$ & 0.790 & 0.43 \\
\hline Males & 177 & & 75 & & & \\
\hline MPS Total & 162 & $185.60(28.43)$ & 72 & $194.60(24.38)$ & -2.331 & $0.021^{\star}$ \\
\hline SOP & 170 & $83.92(16.68)$ & 72 & $85.51(16.15)$ & -0.687 & 0.49 \\
\hline SPP & 169 & $44.14(10.14)$ & 75 & $50.61(11.22)$ & -4.451 & $<0.001^{\star \star}$ \\
\hline OOP & 173 & $45.24(7.32)$ & 75 & $45.56(7.61)$ & -0.310 & 0.76 \\
\hline
\end{tabular}

MPS, Multidimensional Perfectionism Scale; SOP, self-oriented perfectionism; SPP, socially-prescribed perfectionism; OOP, otheroriented perfectionism; $M$, mean; SD, standard deviation.

$t$ (Student); ${ }^{\star} P<0.001 ;{ }^{\star} P<0.05$. 
Table V. Comparisons between the good sleepers and the insomnia groups in total perfectionism and socially-prescribed perfectionism.

\begin{tabular}{|c|c|c|c|c|c|c|c|c|}
\hline \multirow[b]{3}{*}{ Perfectionism } & \multicolumn{4}{|c|}{$\begin{array}{c}\text { Good sleepers } \\
(n=483 ; 306 \mathrm{~F}, 177 \mathrm{M})\end{array}$} & \multicolumn{4}{|c|}{$\begin{array}{c}\text { Insomnia groups } \\
(n=243 ; 168 \mathrm{~F}, 75 \mathrm{M})\end{array}$} \\
\hline & \multirow[b]{2}{*}{$n$} & \multirow[b]{2}{*}{ Mean (SD) } & \multicolumn{2}{|c|}{$\begin{array}{c}\text { Initial } \\
(n=172 ; 122 \mathrm{~F}, 50 \mathrm{M})\end{array}$} & \multicolumn{2}{|c|}{$\begin{array}{c}\text { Maintenance } \\
(n=22 ; 14 \mathrm{~F}, 8 \mathrm{M})\end{array}$} & \multicolumn{2}{|c|}{$\begin{array}{l}\text { Initial/Maintenance } \\
(n=49 ; 32 \mathrm{~F}, 17 \mathrm{M})\end{array}$} \\
\hline & & & $n$ & Mean (SD) & $n$ & Mean (SD) & $n$ & Mean (SD) \\
\hline \multicolumn{9}{|l|}{ MPS Total } \\
\hline Females & 271 & $180.55(26.42)$ & 105 & $187.32(24.46) \star$ & 13 & $190.31(27.61)$ & 27 & $193.41(31.41) \star$ \\
\hline Males & 162 & $185.60(28.43)$ & 47 & $193.74(22.99)$ & 8 & $189.00(29.92)$ & 17 & $199.59(26.12)$ \\
\hline Total & 433 & $182.44(27.27)$ & 152 & $189.31(24.12) \star$ & 21 & $189.81(27.77)$ & 44 & $195.79(29.32) \star \star$ \\
\hline \multicolumn{9}{|l|}{$S P P$} \\
\hline Females & 287 & $42.23(11.41)$ & 114 & $46.97(11.99) \star \star$ & 13 & $47.31(6.93)$ & 30 & $51.97(15.82) \star \star$ \\
\hline Males & 169 & $44.14(10.14)$ & 50 & $49.52(9.98) \star \star$ & 8 & $45.25(11.25)$ & 17 & $56.35(12.98) \star \star$ \\
\hline Total & 456 & $43.03(11.28)$ & 164 & $47.75(11.60) \star \star$ & 21 & $46.33(8.10)$ & 47 & $53.53(14.84) \star \star$ \\
\hline
\end{tabular}

MPS, Multidimensional Perfectionism Scale; SPP, socially prescribed perfectionism.

Comparisons between the control group and insomnia groups were performed using Student's $t$-tests. Significant results are highlighted:

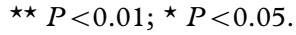

F, females; M, males; SD, standard deviation.

the female sample and $4.3 \%(n=17)$ of the male sample.

With respect to the female sample, total perfectionism was significantly higher in the group of women with initial insomnia alone than in the good sleepers group $(M=187.32, S D=24.46$ vs. $\mathrm{M}=180.55, \quad \mathrm{SD}=26.42 ; \quad t=-2.28 ; \quad \mathrm{df}=374 ;$ $P=0.023)$ and between the group with both initial and maintenance insomnia and the good sleepers group $(M=193.41, S D=31.41$ vs. $M=180.55$, $\mathrm{SD}=26.42 ; t=-2.369 ; \mathrm{df}=296 ; P=0.018$ ) (see Table V). Similar results were found for SPP dimension. Higher values on SPP were found in the group who experienced initial insomnia alone in comparison with the good sleepers group $(\mathrm{M}=46.97, \mathrm{SD}=12$ vs. $\mathrm{M}=42.23, \mathrm{SD}=11.41$; $t=-3.697 ; \mathrm{df}=399 ; P<0.001)$. The group with both initial and maintenance insomnia symptoms also revealed higher SPP in comparison with the good sleepers group $(M=51.97, S D=15.82$ vs. $\mathrm{M}=42.23, \quad \mathrm{SD}=11.41, \quad t=-4.272 ; \quad \mathrm{df}=315$; $P<0.001$ ).

Considering the male sample, although total perfectionism tended to be higher in the group with initial insomnia alone than in the good sleepers group as well as in the group with both initial and maintenance insomnia in comparison with the good sleepers group, results were not statistically significant (group with initial insomnia alone: $M=193.73$, $\mathrm{SD}=22.99$ vs. good sleepers group $\mathrm{M}=185.60$, $\mathrm{SD}=28.43 ; t=-1.800 ; \mathrm{df}=207 ; P=0.073$; both initial and maintenance $M=199.59, S D=26.13$ vs. good sleepers group $\mathrm{M}=185.60, \quad \mathrm{SD}=28.43$; $t=-1.944 ; \mathrm{df}=177 ; P=0.054)$. SPP was significantly higher in the group with initial insomnia alone and in the group with both initial and maintenance insomnia in comparison with the good sleepers group (initial insomnia group: $M=49.52$, $\mathrm{SD}=9.98$ vs. good sleepers group: $\mathrm{M}=44.14$, $\mathrm{SD}=10.14 ; t=-3.307 ; \mathrm{df}=217 ; P=0.001 ;$ initial and maintenance insomnia group: $M=56.35$, $\mathrm{SD}=12.98$ vs. good sleepers group: $\mathrm{M}=44.14$, $\mathrm{SD}=10.14, t=-4.608 ; \mathrm{df}=184 ; P<0.001)$. Significant differences were not found between the group with only maintenance insomnia and the good sleepers group in total MPS as well as in socially prescribed perfectionism. Considering SOP and OOP dimensions all comparisons failed to reveal any significant differences between the three insomnia groups referred above and the good sleepers group (both in male and female samples).

\section{Discussion and conclusions}

In the present study, insomnia symptoms were reported by $22 \%$ of females and $18.8 \%$ of male students. These data are within the range of the prevalence estimates in community epidemiological studies (see Ohayon et al. 2002, for review). Difficulties initiating sleep (DIS) was by far the most common type of sleep disturbance in females $(20.1 \%)$ and males $(12.5 \%)$.

Correlation analyses showed that socially prescribed perfectionism (SPP) is the perfectionism dimension with the highest coefficients across all sleep measures (DIS, difficulties maintaining sleep (DMS) and Sleep Disturbance Index (SDI)), in both genders.

It seems from our results that a small significant relation between sleep disturbance and self-oriented perfectionism (SOP) exists in females, particularly with respect to items related with setting excessively 
high standards and concerns over mistakes. These results are in agreement with the findings of Lundh et al. (1994), that indicate an association between insomnia, personal standards and concern over mistakes and also with the findings of Vincent and Walker (2000), which suggest an association between insomnia and concern over mistakes, a maladaptative perfectionism component.

In both genders, other-oriented perfectionism (OOP) dimension was not significantly correlated with sleep problems.

It may be argued that a large sample size may account for the significance of the correlations found in the present study. Although this may be true, Lundh et al. (1994) obtained significant coefficients with similar magnitudes when studying the association of sleep disturbance and perfectionism in a smaller sample.

Additionally, correlational analyses were done considering the whole sample and not selected extreme groups. This procedure may account for the low coefficients obtained. Another factor that could have influenced the correlations magnitude was the small-scale range of the sleep disturbance variables.

In fact, correlational analyses constituted only the first step of the statistical analyses performed. Further analyses were carried out which substantiated the associations obtained.

Highly socially prescribed perfectionists females were about twice more likely to report sleep disturbances than those with less SPP, and identical results were found when considering women with higher scores on total perfectionism. Similar results were found within the male sample. Males with the highest levels of SPP were 2.6 more likely to report sleep disturbances than those with less SPP. Female and male insomniacs when compared with good sleepers had significantly higher levels of total perfectionism and SPP.

It was also found that those males and females who experienced initial insomnia or both initial and maintenance insomnia symptoms had significantly higher levels of SPP than those in the good sleepers group. These results are in agreement with the findings of Vincent and Walker (2000), which indicated an association between parental criticism (PC) and delayed sleep-onset latency in subjects with chronic insomnia.

Therefore, results from correlational and categorial analyses indicate that SPP is the only perfectionism dimension which is consistently associated with self-reported sleep disturbance in both genders. Of note that although in the study by Vincent and Walker (2000, see Introduction) those with chronic insomnia did not report significantly more SOP,
SPP or OOP relative to healthy controls, there was a trend towards those with insomnia reporting more SPP. Interestingly, in our study the mean scores on this dimension for the insomnia group and good sleepers of both sexes are similar to that found in their chronic insomnia and control group, respectively. On the other hand, they reported significant correlations between insomnia and three factors of Frost's Multidimensional Perfectionism Scale-MPS: "concern over mistakes", "doubts about actions" and "parental criticism", the latter being an interpersonal dimension of perfectionism, just as SPP.

SPP refers to the perception that others have unrealistically high standards for the individual. For example, "people expect nothing less than perfection from me". The individual feels that significant others, like friends, peers and parents are exerting an excessive pressure on him to be perfect. Like other personality dimensions, perfectionism is probably the result of the interaction of biological and developmental/learning factors and is better understood in dimensional terms. It has been found that SPP is positively correlated with others personality dimensions like neuroticism (Hill et al. 1997) which in turn is associated with negative affect.

Shafran and Mansell (2002) speculate that it is probable that perfectionism begins as positive but over time becomes negative, and destructive for a variety of reasons. For example, circumstances can change making it harder to achieve a previously accessible standard. Most of the subjects in our sample are from medicine or dentistry which require the highest grades for admission (in excess of 18 in $20)$. In the years preceding the admission to the university these students have developed high achievement standards and a social image of "perfect" students. But, when entering medical school, many of these individuals cannot live up to the expectations that significant others have created and cannot cope adequately with the pressure that this "web of perfection, in which they are tied up", exerts on them. A possible consequence of this is the development of a cognitive framework with beliefs that the individual is unable to please others, that others are unrealistic in their expectations, and that others will evaluate them negatively. This type of perfectionism, and the set of beliefs that goes with it, primes people to expect negative consequences, resulting in emotional consequences like anxiety, anger, and depression because the standards imposed are felt as excessive and uncontrollable. Congruent with this hypothesis, the main reason for students's self-referral in the outpatient clinic for psychological treatment and counselling at Coimbra University is anxiety disorders and stress-related problems, namely social anxiety and psychological 
distress associated with evaluative concerns (Pereira 2004). As would be expected from its strong relationship with social anxiety, high SPP has been shown to be associated with worry and autonomic arousal during a socially threatening situation (Flett et al. 1995). The association between worry and perfectionism is well established (Stöber and Joorman 2001) and sleeping problems have been reported in worriers, even when trait anxiety was partialled out (Stöber 1995). So, this cognitive arousal may be one of the main links in the chain between perfectionism and sleep problems. It is well known that one of the earliest and most enduring conceptualisations of insomnia is that of psychophysiological arousal. Individuals with insomnia have several indicators of sympathetic and HPA axis activation, together with other peripheral indicators of "arousal" (Buysse and Dorsey 2002). The psychological arousal of insomnia is supported by higher rates of self-reported ruminations and intrusive thoughts among individuals with insomnia. It is less clear whether excess cognitive activity causes insomnia or is simply a by-product of it.

It is not possible from the present study to state that socially prescribed perfectionism is a personality trait which is contributing directly to sleep disturbance in undergraduate students. A mood disorder could be acting as mediator between SPP and sleep. In fact, depression, anxiety or stress are, on the one hand, usually associated with higher levels of SPP and, on the other hand, strong factors influencing sleep quality.

One of the limitations of the present study is that depression and anxiety have not been controlled for. However, in a normal sample the possibility that a mood or anxiety disorder could be acting as the main factor explaining that association is not straightforward. But, even if this hypothesis was real, the causal importance of the trait personality SPP stands out as a primum movens factor indirectly related to sleep problems, in a causal chain from a perfectionist/ worrier prone personality, psychological distress and sleep problems.

In this context, it is important that trait personality SPP could be explored in the future as a predictive factor for the development of sleep problems. In fact, a follow-up of subjects currently in progress will help to clarify the issue of whether high levels of SPP are predictive of sleep problems over time.

\section{Acknowledgements}

The data for this report were drawn from a research on Perfectionism and Obsessive-Compulsive Spectrum Disorders, funded by Fundação para a Ciência e
Tecnologia (FCT - no. 37569/PSI). The co-operation of the Professors and Students of the Faculties studied is gratefully acknowledged. We would equally like to express our gratitude to both Referees who reviewed the manuscript and made helpful comments, criticisms and suggestions.

\section{Statement of interest}

The authors have no conflict of interest with any commercial or other associations in connection with the submitted article.

\section{References}

Buysse DJ, Dorsey CM. 2002. Current and experimental therapeutics of insomnia. In: Davis K, Charney D, Coyle JT, Nemeroff C, editors. Neuropsychopharmacology. The fifth generation of progress. Philadelphia, PA: Lippincott Williams and Wilkins. p 1931-1943.

Cohen J. 1992. A power primer. Psychol Bull 112:155-159.

Enns MW., Cox BJ. 2002. The nature and assessment of perfectionism: a critical analysis. In: Flett GL, Hewitt PL, editors. Perfectionism: theory, research, and treatment. Washington, DC: American Psychological Association. p 33-62.

Flett GL, Hewitt PL. 2002. Perfectionism and maladjustment: an overview of theoretical, definitional, and treatment issues. In: Flett GL, Hewitt PL, editors. Perfectionism: theory, research, and treatment. Washington, DC: American Psychological Association. p 5-31.

Flett GL, Hewitt PL, Endler NS, Tassone C. 1995. Perfectionism and components of state and trait anxiety. Curr Psychol 13:326-350.

Frost RO, Marten P, Lahart C, Rosenblate R. 1990. The dimensions of perfectionism. Cogn Ther Res 14:449-468.

Hewitt PL, Flett GL. 1991. Perfectionism in the self and social contexts: conceptualization, assessment, and association with psychopathology. J Pers Soc Psychol 60:456-470.

Hill RW, McIntire K, Bacharach VR. 1997. Perfectionism and the big five factors. J Soc Behav Pers 12:257-270.

Insel T, Collins F. 2003. Psychiatry in the genomics era. Am J Psychiatry 160:616-620.

Lundh LG, Broman JE, Hetta J, Saboonchi F. 1994. Perfectionism and insomnia. Scand J Behav Ther 23:3-18.

Macedo A, Pocinho F, Soares MJ, et al. 2002. Perfeccionismo uma dimensão fenotípica comum aos fenómenos obsessivos e distúrbios alimentares? [Perfectionism: a phenotype dimension common to obsessive and eating disorders]. Psiq Clín 23:163174.

Macedo A, Soares MJ, Azevedo MH, et al. 2006. Perfectionism and eating attitudes in Portuguese university students. Eur Eat Disord Rev: published online (DOI: 10.1002/erv.735).

Ohayon MM. 2002. Epidemiology of insomnia: what we know and what we still need to learn. Sleep Med Rev 6:97-111.

Pereira AMS. 2004. Concepções e práticas metodológicas em diferentes paradigmas de investigação [Concepts and methodological practices in different research paradigms]. In: Oliveira L, Pereira A, Santiago R, editors. Investigação em Educação. Abordagens Conceptuais e práticas. Porto: Porto Editora. p 47-58.

Shafran R., Mansell W. 2001. Perfectionism and psychopathology: a review of research and treatment. Clin Psychol Rev 21:879906.

Soares MJ, Gomes AA, Macedo AF, Santos V, Azevedo MHP. 2003. Escala multidimensional de perfeccionismo: adaptação à 
população portuguesa [The Multidimensional Perfectionism Scale: adaptation to the Portuguese population]. Rev Port Psicossom 5:46-55.

Stöber J. 1995. Besorgnis: Ein Vergleich dreier Inventare zur Erfassung allgemeiner Sorgen [Worry: A comparison of three questionnaires for the assessment of general worries]. $\mathrm{Z}$ Differentielle Diagnost Psychol 16:50-63.
Stöber J, Joorman J. 2001. Worry, proscrastination and perfectionism: differentiating amount of worry, pathological worry, anxiety and depression. Cogn Ther Res 25:49-60.

Vincent NK, Walker JR. 2000. Perfectionism and chronic insomnia. J Psychosom Res 49:349-54. 